DOMINGOS, R. A. F., MENDES, M. da C. B. R., OLIVEIRA, D. DA S., COSTA, N. M. V. N. Qualificação acadêmica e profissional dos docentes de cursos de direito em Angola: uma análise com base nos planos de desenvolvimento institucionais

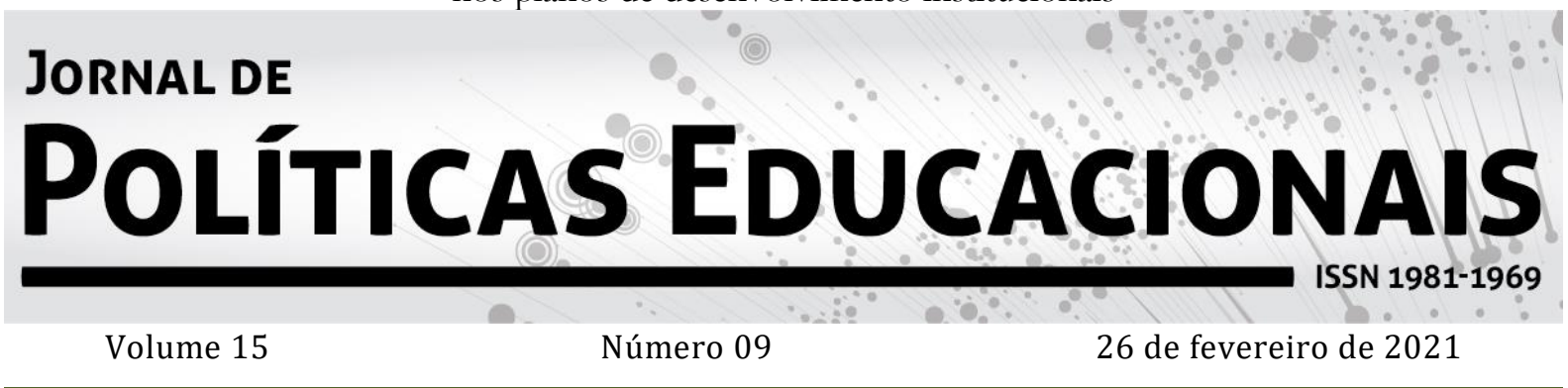

\title{
Qualificação acadêmica e profissional dos docentes de cursos de direito em Angola: uma análise com base nos planos de desenvolvimento institucionais ${ }^{1}$
}

\section{Academic and professional qualification of law course teachers in Angola: an analysis based on institutional development plans}

\section{Cualificación académica y profesional de los docentes de cursos de derecho en Angola: un análisis basado en planes de desarrollo institucional}

\author{
Rangel Assunção Francisco Domingo ${ }^{2}$ \\ Maria da Conceição Barbosa Rodrigues Mendes ${ }^{3}$ \\ Diana da Silva Oliveira ${ }^{4}$ \\ Nilza Maria Vilhena Nunes Costa
}

\footnotetext{
${ }^{1}$ Este trabalho é financiado por Fundos Nacionais através da FCT - Fundação para a Ciência e a Tecnologia, I.P., no âmbito do projeto UIDB/00194/2020.

${ }^{2}$ Doutorando em Educação pela Universidade de Aveiro, Portugal. Vice-Decano da Faculdade de Direito da Universidade Mandume Ya Nedemufayo, Angola. Investigador do Laboratório de Supervisão e Avaliação Lab_SuA do Centro de Pesquisa "Didática e Tecnologia na Educação de Formadores" / CIDTFF do Departamento de Educação e Psicologia Universidade de Aveiro. Luanda, Angola. Orcid: https://orcid.org/0000-0001-6151-3860. Email: rangeldomingos@ reitoria.umn.ed.ao ${ }^{3}$ Professora Catedrática da Universidade Katyavala Bwila, Angola é doutorada em Administração Escolar e mestre em Teoria e Desenvolvimento Curricular. É docente há mais de 30 anos. A actuação científica inscreve-se na linha de investigação "Políticas e Práticas de Gestão no Ensino Superior". Luanda, Angola. Orcid: https://orcid.org/0000-0003-4904-7056. E-mail: saobarbosa67@yahoo.com.br 4 Investigadora do Laboratório de Supervisão e Avaliação Lab_SuA do Centro de Pesquisa "Didática e Tecnologia na Educação de Formadores" / CIDTFF do Departamento de Educação e Psicologia Universidade de Aveiro é doutorada em Educação pela Universidade de Aveiro, Portugal. Aveiro, PT. Orcid: https://orcid.org/0000-0002-5434-1818. E-mail: diana.oliveira@ua.pt 5 Professora Catedrática aposentada da Universidade de Aveiro (Portugal) e investigadora integrada do Centro de Investigação "Didática e Tecnologia na Formação de Formadores" - CIDTFF. Os seus principais interesses de investigação são a Formação de Professores (do ensino secundário ao ensino superior), Avaliação e Avaliação e Desenvolvimento de Pessoal de Professores (do ensino secundário ao ensino superior). Foi coordenadora do CIDTFF entre 2012 e 2016 e coordenadora do Laboratório de Supervisão e Avaliação (Lab_SuA) . Aveiro, PT. Orcid: https://orcid.org/0000-0002-1707-9697. E-mail: nilzacosta@ua.pt
} 
DOMINGOS, R. A. F., MENDES, M. da C. B. R., OLIVEIRA, D. DA S., COSTA, N. M. V. N. Qualificação acadêmica e profissional dos docentes de cursos de direito em Angola: uma análise com base nos planos de desenvolvimento institucionais

Citação: DOMINGOS, R. A. F., MENDES, M. da C. B. R., OLIVEIRA, D. DA S., COSTA, N. M. V. N. Qualificação acadêmica e profissional dos docentes de cursos de direito em Angola: uma análise com base nos planos de desenvolvimento institucionais. Jornal de Políticas Educacionais. V. 15, n. 09. Fevereiro de 2021.

\title{
http://10.5380/jpe.v15i0.78566
}

\section{Resumo}

A qualificação do corpo docente é uma das dimensões fundamentais da gestão organizacional das instituições de ensino superior/IES. Este artigo aborda a qualificação acadêmica e profissional docente/QAPD nos cursos de Direito em IES públicas Angolanas, através da análise documental de como esta é integrada em cinco Planos de Desenvolvimento Institucionais/PDI das sete Universidades públicas do País que ministram os referidos cursos. Esta análise, feita com base num instrumento desenvolvido pelos autores, foi precedida da construção de um referencial normativo e teórico, sobre a QAPD de docentes do Ensino Superior em geral, e da área do Direito em particular. Os resultados evidenciam que as referências à QAPD são muito gerais, o que parece remeter os PDI a um procedimento burocrático de regulação. Como implicações do estudo sugere-se que se aprofundem os resultados analisando outros documentos institucionais relacionados à operacionalização dos PDI das Faculdades de Direito.

Palavras-chave Qualificação acadêmica e profissional, Docente de Cursos de Direito em Angola, Plano de Desenvolvimento Institucional, Ensino Superior.

\begin{abstract}
Teachers' qualification has been referred as one of the fundamental dimensions of organizational management of higher education institutions/HEI. This article addresses the academic and professional qualification of teachers/APQT in Law Degrees in Angolan public HEI, through documental analysis of how APQT is integrated in five Institutional Development Plans/IDP of the seven public Universities in the country that deliver those degrees. This analysis, based on an instrument developed by the authors, was preceded by the construction of a normative and theoretical framework about the APQT of higher education teachers, in general, and in the area of Law in particular. The results show that references to APQT are very general, which seems that IDP are mainly a bureaucratic and regulatory procedure. As implications of the study, it is suggested to deepen the results by analyzing other institutional documents of Law Faculties related with the IDP operationalization
\end{abstract}

Keywords: Academic and professional qualification, Teachers of Law Degrees in Angola, Institutional Development Plan, Higher education.

\section{Resumen}

La cualificación del profesorado ha sido referida como una de las dimensiones fundamentales de la gestión organizacional de las instituciones de educación superior/IES. El artículo aborda la calificación académica y profesional de los docentes/QAPD en cursos de Derecho en las IES públicas angoleñas, por medio del análisis documental de cómo se integra en cinco Planes de Desarrollo Institucional/PDI de las siete Universidades públicas que imparten estos cursos. Este análisis, basado en un instrumento desarrollado por los autores, fue precedido por la construcción de un marco normativo-legal y teórico, sobre el QAPD de los docentes de Educación Superior, en particular del área de Derecho. Los resultados muestran que las referencias a QAPD son muy generales, lo que parece remitir a los PDI a un procedimiento regulatorio burocrático. Como implicaciones del estudio, se sugiere analizar otros documentos institucionales de facultades de Derecho relacionados con la operacionalización del PDI. Resumen em espanhol com no máximo 230 (duzentas e trinta) palavras - (fonte cambria 10, alinhamento justificado, espaço simples)

Palabras clave: Cualificación académica y profesional. Profesor de Cursos de Derecho en Angola. Plan de desarrollo institucional. Enseñanza superior.

\section{Introdução}


DOMINGOS, R. A. F., MENDES, M. da C. B. R., OLIVEIRA, D. DA S., COSTA, N. M. V. N. Qualificação acadêmica e profissional dos docentes de cursos de direito em Angola: uma análise com base nos planos de desenvolvimento institucionais

A expansão do ensino superior/ES nas últimas décadas elevou, consideravelmente, a oferta de cursos de Direito em Angola, ampliando a demanda docente. Assim, a qualificação acadêmica e profissional docente/QAPD em Angola tem marcado a política educativa e a atenção dos atores do subsistema de ES. A revisão do Estatuto da Carreira Docente do ES/ECDES (ANGOLA, 2018) expressa esta preocupação.

Pretende-se, com este estudo, analisar como a QAPD em cursos de Direito de Instituições de Ensino Superior/IES públicas Angolanas é integrada nos Plano de Desenvolvimento Institucional/PDI, documento este de caráter obrigatório e que deve corporizar os elementos identitários e estruturantes das instituições e respetivas linhas de intervenção.

Este artigo encontra-se estruturado em quatro secções. Na primeira, sintetiza-se o enquadramento teórico e normativo da QAPD, procurando aferir o que é que a literatura e a legislação propõem sobre o perfil do docente do ES, em particular na área do direito, e a forma como esse perfil é incluído nos PDI; na segunda, apresenta-se a proposta metodológica que sustenta o estudo; na terceira secção apresentam-se os principais resultados encontrados e respetiva discussão; e, por fim, apresentam-se as considerações finais.

\section{Enquadramento teórico e normativo}

O referencial teórico e normativo enquadrador do estudo inclui duas subsecções centradas, por um lado, no que a literatura consultada advoga sobre o perfil do docente do ES em geral, e em particular sobre o perfil do docente de cursos de Direito; por outro, os principais normativos sobre a QAPD no ES em Angola, e como se espera que esta seja contemplada nos PDI.

\subsection{Perfil do docente do es em geral e da área do direito}

O perfil de um docente do ES (ALARCÃO, 2001; ROLDÃO, 2017) constitui-se pelas características essenciais que descrevem as ações, atividades e as circunstâncias em que o profissional executa as suas tarefas. Todavia, quando se estuda o seu perfil é imprescindível perceber os elementos necessários à construção dos saberes profissionais e à sustentabilidade desses elementos na ação, ou seja, o perfil desejado de acordo com a 
DOMINGOS, R. A. F., MENDES, M. da C. B. R., OLIVEIRA, D. DA S., COSTA, N. M. V. N. Qualificação acadêmica e profissional dos docentes de cursos de direito em Angola: uma análise com base nos planos de desenvolvimento institucionais

área de atuação (ROLDÃO, 2017). Chipeata (2018) sistematiza, com base em diferentes autores, os princípios, conhecimentos, saberes e competências necessárias à docência no ES (Tabela 1).

Tabela 1. Princípios, conhecimentos, saberes e competências necessárias à docência no ES

\begin{tabular}{|c|c|c|}
\hline Tipologia & Autor & Indicadores \\
\hline \multirow{3}{*}{ Princípios de base } & \multirow{3}{*}{$\begin{array}{l}\text { Nóvoa } \\
\text { (2017) }\end{array}$} & 1) Disposição pessoal; \\
\hline & & 2) Interposição Profissional; \\
\hline & & 3) Composição Pedagógica. \\
\hline \multirow{10}{*}{$\begin{array}{l}\text { Conhecimentos } \\
\text { necessários à docência }\end{array}$} & \multirow{7}{*}{$\begin{array}{l}\text { Shulman } \\
(2005)\end{array}$} & 1) Conhecimento do conteúdo; \\
\hline & & 2) Conhecimento pedagógico; \\
\hline & & 3) Conhecimento do curriculum; \\
\hline & & 4) Conhecimento dos alunos e da \\
\hline & & aprendizagem; \\
\hline & & 5) Conhecimento dos contextos educativos; \\
\hline & & 6) Conhecimento didático do conteúdo. \\
\hline & \multirow{3}{*}{$\begin{array}{l}\text { Garcia } \\
\text { (1992) }\end{array}$} & 1) Conhecimento pedagógico geral; \\
\hline & & 2) Conhecimento do conteúdo; \\
\hline & & 3) Conhecimento didático do conteúdo. \\
\hline \multirow{8}{*}{$\begin{array}{l}\text { Saberes necessários à } \\
\text { docência }\end{array}$} & \multirow{8}{*}{$\begin{array}{l}\text { Cunha } \\
\text { (2004) }\end{array}$} & 1) Saberes sobre a prática pedagógica; \\
\hline & & 2) Saberes sobre o ambiente de aprendizagem; \\
\hline & & 3) Saberes sobre o contexto sócio histórico dos \\
\hline & & alunos; \\
\hline & & 4) Saberes sobre o planeamento das atividades \\
\hline & & de ensino; \\
\hline & & 5) Saberes sobre a condução da aula; \\
\hline & & 6) Saberes sobre a avaliação da aprendizagem. \\
\hline \multirow{4}{*}{$\begin{array}{l}\text { Competências } \\
\text { necessárias à docência }\end{array}$} & \multirow{4}{*}{$\begin{array}{l}\text { Zaballa } \\
(2006)\end{array}$} & 1) Planificar o processo de ensino e \\
\hline & & aprendizagem; \\
\hline & & 2) Selecionar e preparar os conteúdos \\
\hline & & disciplinares; \\
\hline
\end{tabular}


DOMINGOS, R. A. F., MENDES, M. da C. B. R., OLIVEIRA, D. DA S., COSTA, N. M. V. N. Qualificação acadêmica e profissional dos docentes de cursos de direito em Angola: uma análise com base nos planos de desenvolvimento institucionais

3) Oferecer informações e explicações compreensíveis;

4) Comunicar e relacionar-se com os alunos;

\begin{tabular}{ll}
\hline & 1) Organizar e dirigir situações de \\
& aprendizagem; \\
Perrenoud & 2) Administrar a progressão das \\
aprendizagens; \\
$(2000)$ & 3) Conceber e fazer evoluir os dispositivos de \\
diferenciação pedagógica; & 4) Envolver os alunos em suas aprendizagens;
\end{tabular}

Fonte: Adaptado de Chipeata (2018).

Chipeata (2018) considera que o perfil do docente do ES deve ser enquadrado na lógica de um paradigma integrador centrado em princípios, conhecimentos, saberes e competências, permitindo: a) autonomia docente; b) participação docente nos processos de legitimação das políticas educativas; c) ética e coerência docente; 4) crítica e autocrítica (ESQUINSANI; SOBRINHO, 2020). O perfil não se deve limitar a uma dimensão técnica, enquanto somatória de destrezas cognitivas concretas, devendo mobilizar experiências e competências inerentes à contextualização pedagógica, a conformação de saberes, numa lógica transformadora e (re)construtiva, integrando aprendizagens contínuas, de caráter formal ou não formal, transcendem a mera aquisição de conhecimentos e destrezas (MOREIRA; 2020).

Em Angola, a história do ensino na área do Direito 1980 (UAN, 2019), foi estruturado para responder às necessidades do Estado de formar profissionais com qualificações específicas, e com recurso à colaboração de especialistas da área de direito (advogados, promotores de justiça, juízes de direito) com profundo conhecimento técnico, porém com uma enorme deficiência didática (PONCE, 2011), e sujeitos a modelo de aulas limitando-se a transmissão formal dos conteúdos, muitas vezes avesso às formulações críticas, (MADERS; DUARTE 2017).

Em consequência, os mesmos autores, com base em diferentes estudos, sistematizam um conjunto de problemas existentes no ensino da área do Direito (por exemplo, abordagens dogmáticas e acríticas), propondo soluções concretas (Tabela 2). 
DOMINGOS, R. A. F., MENDES, M. da C. B. R., OLIVEIRA, D. DA S., COSTA, N. M. V. N. Qualificação acadêmica e profissional dos docentes de cursos de direito em Angola: uma análise com base nos planos de desenvolvimento institucionais

Tabela 2. Problemas e soluções relacionados com a docência no ES na área do Direito

\begin{tabular}{|c|c|c|}
\hline Autor & Problemas & Soluções \\
\hline $\begin{array}{l}\text { Horácio } \\
\text { Rodrigues }\end{array}$ & $\begin{array}{l}\text { Dogmatismo; tecnicista; } \\
\text { tradicionalismo; elitista; falta de } \\
\text { pesquisa; vaidade docente. }\end{array}$ & $\begin{array}{l}\text { Reforma curricular; novas } \\
\text { dinâmicas de aulas; disciplinas } \\
\text { transversais. }\end{array}$ \\
\hline $\begin{array}{l}\text { Luís } \\
\text { Warat }\end{array}$ & $\begin{array}{l}\text { Tradicionalismo; vaidade docente; } \\
\text { falta de formação crítica. }\end{array}$ & $\begin{array}{l}\text { Novas dinâmicas de aulas; } \\
\text { conscientização política; } \\
\text { formação crítica. }\end{array}$ \\
\hline José Faria & $\begin{array}{l}\text { Dogmatismo; tecnicismo; } \\
\text { tradicionalista; elitista; falta de } \\
\text { formação humanística. }\end{array}$ & $\begin{array}{l}\text { Reforma curricular; cosmovisão } \\
\text { jurídica; formação humanística; } \\
\text { formação crítica. }\end{array}$ \\
\hline $\begin{array}{l}\text { Eduardo } \\
\text { Bittar }\end{array}$ & $\begin{array}{l}\text { Elitista; profissionalizante; falta de } \\
\text { pesquisa; falta de formação crítica. }\end{array}$ & $\begin{array}{l}\text { Reforma pedagógica e } \\
\text { curricular; valorização do } \\
\text { professor. }\end{array}$ \\
\hline $\begin{array}{l}\text { Roberto } \\
\text { Filho }\end{array}$ & $\begin{array}{l}\text { Elitista; dogmático; reacionário; } \\
\text { transmissão de poder; } \\
\text { reducionismo; falta de formação } \\
\text { crítica. }\end{array}$ & $\begin{array}{l}\text { Reforma jurídica e } \\
\text { epistemológica; formação } \\
\text { critica. }\end{array}$ \\
\hline
\end{tabular}

Fonte: Adaptado de Maders e Duarte (2017).

No conjunto de soluções apresentadas, a formação pedagógica dos docentes é a mais referenciada, ressaltando a indispensabilidade de uma pedagogia universitária no processo de formação do docente do ES. Entretanto, a pedagogia na educação superior revela-se um campo problemático, sendo que muitos dos docentes em exercício não possuem formação pedagógica, podendo isso resultar no desgaste profissional e insatisfação dos alunos, brindo caminhos para a oferta de cursos de apropriação de conhecimentos necessários para exercer a profissão. (DAMASCENO; FONTES, 2019)

O exercício da docência por profissionais docentes e não por docentes profissionais constitui um desvio, tanto normativo como técnico, que pode induzir o amadorismo que, como refere (FONTAINHA, 2010), pode afetar o compromisso destes profissionais para com a missão docente. 0 exercício da docência, nesta circunstância, é assumido como forma de ascensão social pois, para Milkiewicz e Pedro (2020), além da 
DOMINGOS, R. A. F., MENDES, M. da C. B. R., OLIVEIRA, D. DA S., COSTA, N. M. V. N. Qualificação acadêmica e profissional dos docentes de cursos de direito em Angola: uma análise com base nos planos de desenvolvimento institucionais

ausência de formação didático-pedagógica, os docentes tendem a encarar a lecionação como uma mera complementaridade da atividade profissional fundamental.

Assim, e de acordo com Milkiewicz e Pedro (2020), é necessário refletir sobre as formas através das quais os docentes podem estimular a reflexão, a produção e a compreensão do Direito, e a sua própria atuação profissional, buscando meios para melhorar a qualidade de ensino e uma vinculação com a área da Didática e da Pedagogia do Direito.

Nesse contexto, o perfil de um docente do ES da área do Direito assume natureza multidimensional, agregando conhecimentos, saberes e competências que permitam o distanciamento de práticas tradicionalistas, e a aproximação à didática construtiva e reflexiva. Para que isso aconteça, os PDI das Faculdades de Direito/FD deverão prever especificidades no perfil docente e respetivos planos de formação e superação permanente, legitimando a gestão estratégica do corpo docente, e a promoção da qualidade educativa.

\subsection{A qualificação docente no plano normativo}

Para aferir o perfil do docente do ES, expresso no ECDES, documento reitor da carreira docente no ES em Angola (ANGOLA, 2018), procurou-se compreender e enquadrar a perspetiva normativa predominante pois, a regulação estatal assume uma forma de intervenção que pode ser visível, quando efetuada por normas que buscam atingir objetivos (LINDOSO; DOS SANTOS 2019), considerando a indiferenciação ou a diferenciação da função docente, associando a estandardização das capacidades, expressa numa formação de base e em competências específicas requeridas para a docência universitária (FORMOSINHO; MACHADO; OLIVEIRA-FORMOSINHO, 2010)

Assim foi realizada uma análise dos referenciais que sustentam o perfil docente em quatro dimensões - acadêmica, investigativa, pedagógica e profissional - sintetizando-se os seus principais indicadores e traços (Tabela 3).

Tabela 3. Caracterização normativa do perfil docente do ES

Dimensão Indicadores do perfil Principais traços


DOMINGOS, R. A. F., MENDES, M. da C. B. R., OLIVEIRA, D. DA S., COSTA, N. M. V. N. Qualificação acadêmica e profissional dos docentes de cursos de direito em Angola: uma análise com base nos planos de desenvolvimento institucionais

\begin{tabular}{|c|c|c|}
\hline Acadêmica & $\begin{array}{l}\text { - Titulação; } \\
\text {-Especialização } \\
\text { formativa na área da } \\
\text { docência. }\end{array}$ & $\begin{array}{l}\text { - Valorização do título de Doutor, Mestre e } \\
\text { Licenciado para o acesso e provimento na } \\
\text { carreira. }\end{array}$ \\
\hline Investigativa & $\begin{array}{l}\text { - Produção científica; } \\
\text {-Participação em } \\
\text { eventos científicos } \\
\text { nacionais } \\
\text { internacionais; } \\
\text {-Participação em } \\
\text { júris de Provas } \\
\text { Públicas } \\
\text { (licenciatura, } \\
\text { mestrado } \\
\text { doutoramento). }\end{array}$ & $\begin{array}{l}\text { - Incentivo à inovação científica na área de } \\
\text { especialização; } \\
\text {-Incentivo à produção de materiais } \\
\text { pedagógicos (livros didáticos); } \\
\text {-Incentivo à produção científica } \\
\text { (comunicações, artigos em revistas } \\
\text { científicas); } \\
\text {-Valorização da internacionalização e da } \\
\text { mobilidade docente. }\end{array}$ \\
\hline Pedagógica & - Aptidão pedagógica. & $\begin{array}{l}\text { - Institucionalização de Provas Públicas } \\
\text { como mecanismos de aferição da aptidão } \\
\text { pedagógica e científica. }\end{array}$ \\
\hline Profissional & $\begin{array}{l}\text {-Experiência } \\
\text { exercício } \\
\text { docência; } \\
\text {-Desempenho } \\
\text { profissional. }\end{array}$ & $\begin{array}{l}\text { - Valorização do tempo de serviço (mínimo } \\
5 \text { anos); } \\
\text { - Gestão da carreira por via da avaliação do } \\
\text { desempenho docente como um mecanismo } \\
\text { de aferição do grau de cumprimento das } \\
\text { funções atribuídas. }\end{array}$ \\
\hline
\end{tabular}

Fonte: Elaborado pelos autores (2020).

A dimensão acadêmica estabelece como perfil desejado as titulações de Mestre e de Doutor para o ingresso e o provimento na classe de professores, integrada em três categorias (Professor Catedrático, Professor Associado e Professor Auxiliar), embora, como indicado na Tabela 3, também possa ser o de Licenciado. 0 grau de Mestre é válido para o acesso à categoria de Assistente Decreto n. 191/18, (ANGOLA, 2018).

A dimensão investigativa é tida como relevante dada a sua transversalidade para o cumprimento das funções docentes subjacentes ao ensino, à investigação e à extensão 
DOMINGOS, R. A. F., MENDES, M. da C. B. R., OLIVEIRA, D. DA S., COSTA, N. M. V. N. Qualificação acadêmica e profissional dos docentes de cursos de direito em Angola: uma análise com base nos planos de desenvolvimento institucionais

universitária, reportadas como responsabilidades do docente do ES Decreto n. 191/18, (ANGOLA, 2018), sobressaindo uma lógica de gestão da carreira docente centrada no conhecimento, constituindo-se este um dos elementos diferenciadores da universidade .

A dimensão pedagógica faz parte dos critérios necessários para a ascensão às três categorias da classe de Professor. As mesmas são referenciadas como mecanismos para aferir a aptidão pedagógica e a capacidade científica do candidato Decreto n. 191/18, (ANGOLA, 2018).

A dimensão profissional é ligada à experiência no exercício da docência e da quantificação do tempo de serviço, num mínimo de cinco anos. Apenas o provimento à categoria de Professor Associado beneficia de excecionalidade, sendo permitida a promoção com o mínimo de 3 anos de efetividade na categoria precedente Decreto n. 191/18, (ANGOLA, 2018).

Em síntese, para cada uma das categorias são estabelecidos critérios de acesso e de provimento que transpõem a mera titulação acadêmica, incorporando indicadores relacionados com competências profissionais e investigativas (Tabela 4).

Tabela 4. Critérios de provimento na carreira Vs traços de qualificação acadêmicoprofissional

\begin{tabular}{|c|c|c|}
\hline $\begin{array}{l}\text { Categoria } \\
\text { docente }\end{array}$ & Critérios de provimento & Traços de QAPD \\
\hline \multirow{6}{*}{$\begin{array}{l}\text { Professor } \\
\text { Catedrático }\end{array}$} & \multirow{6}{*}{$\begin{array}{l}\text { - Grau de Doutor; } \\
\text { - Tempo de permanência na categoria } \\
\text { antecedente (5 anos); } \\
\text { - Avaliação positiva do desempenho; } \\
\text { - Produção científica relevante. }\end{array}$} & -Valorização da titulação \\
\hline & & -Valorização da antiguidade \\
\hline & & $\begin{array}{l}\text { na carreira; } \\
\text {-Valorização do }\end{array}$ \\
\hline & & desenvolvimento \\
\hline & & profissional; \\
\hline & & $\begin{array}{l}\text {-Incentivo à investigação e à } \\
\text { produção científica. }\end{array}$ \\
\hline & - Grau de Doutor; & \\
\hline $\begin{array}{l}\text { Protessor } \\
\text { Associado }\end{array}$ & $\begin{array}{l}\text { - Tempo de permanência na categoria } \\
\text { antecedente ( } 5 \text { anos); }\end{array}$ & $\begin{array}{l}\text {-Valorizaçao da titulaçao } \\
\text { acadêmica; }\end{array}$ \\
\hline
\end{tabular}


DOMINGOS, R. A. F., MENDES, M. da C. B. R., OLIVEIRA, D. DA S., COSTA, N. M. V. N. Qualificação acadêmica e profissional dos docentes de cursos de direito em Angola: uma análise com base nos planos de desenvolvimento institucionais

- Avaliação positiva do desempenho; $\quad$-Valorização da antiguidade

- Aprovação em provas de aptidão na carreira;

pedagógica

-Valorização da competência

- Produção científica;

profissional;

-Orientação de teses de Doutoramento. - -Incentivo à investigação e à produção científica.

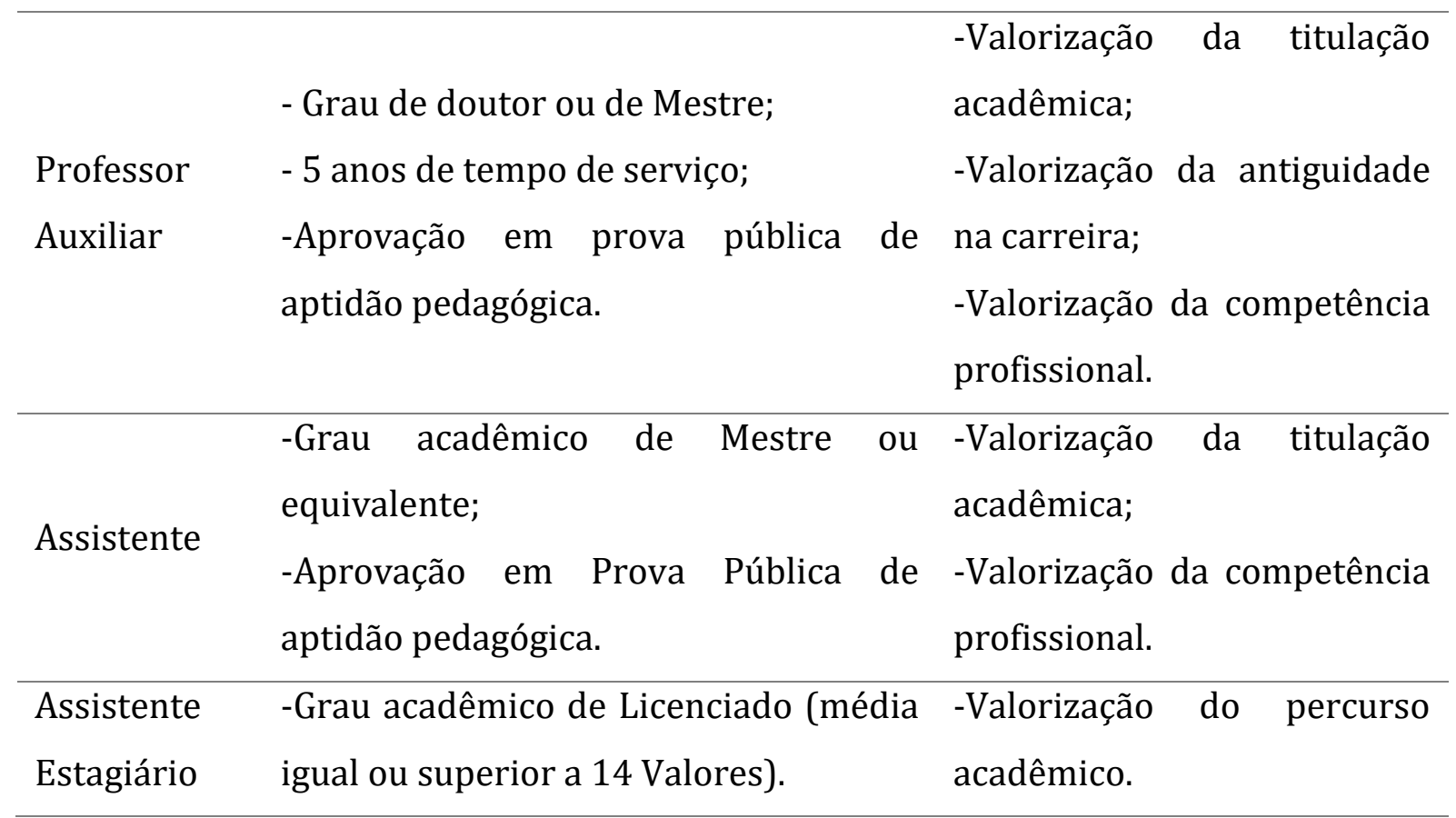

Fonte: Elaborado pelos autores (2020).

Enquanto instrumento estratégico de gestão organizacional, o PDI prevê, para além dos elementos identitários da instituição, estratégias relacionadas com a gestão do corpo docente, pois o desenvolvimento desse recurso integra os princípios de gestão das universidades modernas (BRASIL, 2006).

Considerando a autoridade do Estado como uma das forças de coordenação e de controlo da atividade das universidades (ESQUINSANI; SOBRINHO, 2020), muitos Governos estabelecem diretrizes estruturantes do PDI. Tal é o caso do Brasil que, no Decreto n.o 5.773 de 09 de maio, regula a elaboração dos PDI. De modo geral, as diretrizes em relação ao perfil docente (BRASIL, 2006) estabelecem os seguintes elementos: a) Composição (titulação, regime de trabalho, experiência acadêmica e experiência profissional); b) Plano de Carreira; c) Critérios de seleção e contratação; d) Cronograma e plano de expansão do corpo docente. 
DOMINGOS, R. A. F., MENDES, M. da C. B. R., OLIVEIRA, D. DA S., COSTA, N. M. V. N. Qualificação acadêmica e profissional dos docentes de cursos de direito em Angola: uma análise com base nos planos de desenvolvimento institucionais

Em Angola, o processo de elaboração do PDI é estabelecido, apenas na generalidade. Encontram-se referências avulsas em documentos legislativos nomeadamente: a) Resolução n.o 4/07, (ANGOLA, 2007); b) Decreto n. 26 e 27/11 (ANGOLA, 2011); c) Lei n. 32/20, (ANGOLA, 2020); d) Decreto n. 90/09, (ANGOLA, 2009). Constituindo apenas uma referência normativa para a ação (SILVA, 2016), sem excluir a lógica tendencialmente burocrática, enquanto requisito legal para a autorização da criação de IES e respetivos cursos. No entanto, não existem normativos específicos sobre a estruturação do PDI. Considera-se que, dada a natureza e especificidades implícitas ao PDI, mormente a sua dimensão estratégica para a concretização das políticas educativas e para a operacionalização da gestão organizacional, é fundamental a sua regulamentação, de modo a salvaguardar o princípio da harmonização.

\section{Metodologia}

Metodologicamente, optou-se por um estudo do tipo exploratório interpretativo, de natureza qualitativa, e com recurso a análise documental como técnica de análise de dados. Foram contactadas, por e-mail e/ou telefone, as Secretarias Gerais e/ou os Gabinetes dos Reitores de todas as Universidades Públicas Angolanas que ministram cursos de Direito (sete no total), tendo sido solicitado o PDI em vigor. Obtiveram-se os PDI de cinco Universidades, codificadas em U1, U2, U3, U4 e U5 (Tabela 5).

Tabela 5. Codificação das cinco Universidade Públicas Angolanas e respetivo prazo de vigência dos PDI

\begin{tabular}{cc}
\hline $\begin{array}{c}\text { Universidades Públicas Angolanas } \\
\text { com cursos de Direito }\end{array}$ & $\begin{array}{c}\text { Prazo de vigência dos PDI } \\
\text { recolhidos }\end{array}$ \\
\hline U1 & $2009-2019$ \\
\hline U2 & $2017-2022$ \\
\hline U3 & $2017-2021$ \\
\hline U4 & $2016-2024$ \\
\hline
\end{tabular}


DOMINGOS, R. A. F., MENDES, M. da C. B. R., OLIVEIRA, D. DA S., COSTA, N. M. V. N. Qualificação acadêmica e profissional dos docentes de cursos de direito em Angola: uma análise com base nos planos de desenvolvimento institucionais

\section{U5 2013-2023}

Fonte: Elaborado pelos autores (2020).

Procurando compreender como é que os PDI integram a QAPD, estes foram examinados tendo por base o Instrumento de Análise (IA) anteriormente desenvolvido e validado (AUTORES, 2021). Assim, e de acordo com a estrutura do IA, os resultados são apresentados em função das quatro dimensões seguintes:

1. Formação e desenvolvimento acadêmico e profissional;

2. Ensino (competência pedagógica);

3. Investigação (competência científica);

4. Extensão (competência para disseminar o saber acadêmico).

De acordo ainda com o IA os resultados (ver secção seguinte, Tabela 6, 7, 8, 9 e 10) são apresentados com base em duas escalas: binária e tipo Likert. A primeira (SIM/NÃO) refere-se ao critério de existência ou não do referido indicador. A escala do tipo Likert sinaliza o grau de intensidade da manifestação do indicador, estruturada em 5 níveis (1 “Nada”, 2 "Pouco", 3 “Algo", 4 "Bastante" e 5 "Muito”). Para além disso são apresentados excertos ilustrativos retirados dos PDI analisados.

\section{Resultados e discussão}

Seguindo a estrutura do IA utilizado, apresentam-se os resultados de acordo com a ordem das dimensões indicadas na secção anterior. Assim, na Tabela 6 sintetizam-se os principais resultados da dimensão "Formação e desenvolvimento acadêmico e profissional".

Tabela 6. Resultados da dimensão "Formação e desenvolvimento acadêmico e profissional", por PDI de cada Universidade

$$
\text { Indicadores }
$$

Escala

U1 U2 U3 U4 U5

...define as competências do perfil de entrada para

$\begin{array}{lllllllllll}\mathrm{i} & \text { os docentes em conformidade com } & \text { o } & \text { curso } & 4 & 2 & 3 & 3 & 2\end{array}$ ministrado 
DOMINGOS, R. A. F., MENDES, M. da C. B. R., OLIVEIRA, D. DA S., COSTA, N. M. V. N. Qualificação acadêmica e profissional dos docentes de cursos de direito em Angola: uma análise com base nos planos de desenvolvimento institucionais

\begin{tabular}{|c|c|c|c|c|c|c|}
\hline ii & $\begin{array}{l}\text {...tem em conta a experiência profissional para a } \\
\text { contratação docente }\end{array}$ & 2 & 2 & 2 & 2 & 2 \\
\hline iii & $\begin{array}{l}\text {...inclui nos critérios de entrada para a carreira } \\
\text { docente a aferição das competências pedagógicas }\end{array}$ & 2 & 4 & 3 & 3 & 3 \\
\hline iv & $\begin{array}{l}\text {...define os requisitos para entrada na carreira } \\
\text { docente universitária }\end{array}$ & Sim & Sim & Sim & Sim & $\mathrm{Sim}$ \\
\hline $\mathrm{V}$ & $\begin{array}{l}\text {...exige um nível de formação enquadrado na } \\
\text { carreira do ES }\end{array}$ & Sim & Sim & Não & Não & $\mathrm{Sim}$ \\
\hline vi & $\begin{array}{l}\text {...elenca a formação científica na área de } \\
\text { conhecimento como um dos requisitos de entrada } \\
\text { na carreira docente }\end{array}$ & Sim & Não & $\mathrm{Sim}$ & Sim & Não \\
\hline
\end{tabular}

Fonte: Elaborado pelos autores (2020).

O PDI da U2 é aquele que maior relevância atribui (nível 4) ao indicador (i). 0 indicador (ii) é o que surge com o nível mais baixo (nível 2) em todos PDI. A U2 é a instituição que maior relevância atribui ao indicador (iii) (nível 4). Relativamente ao indicador (iv), todos os PDI fazem alusão a este indicador (SIM). O mesmo não se observou no indicador (v) em apenas três PDI (U1, U2 e U5) se verificou a sua presença (SIM). Quanto ao último indicador (vi), registou-se a presença (SIM) também em apenas três PDI (U1, U3 e U4). Com recurso aos seguintes excertos ilustra-se a presença de alguns indicadores nos PDI analisados:

Excertos: "Critérios a ter em conta no processo de contração do Corpo Docente: Categoria profissional; qualificação; Regime de laboral; Nacionalidade" (U2, p. 33); "Enquadramento das qualificações do corpo Docente existente com requisitos mínimos para ministrar cursos atuais (graduação ou pós-graduação)" (U1, p. 89);

Os resultados encontrados evidenciam que, os PDI analisados atribuem pouca relevância (níveis inferiores a 4 e NÃO), aos indicadores que compõem o IA, com exceção do indicador (iv) (SIM em todos os PDI). Este resultado pode estar relacionado com o facto de a perceção dos diferentes elementos intrínsecos ao perfil de entrada do docente, em especial os inerentes ao curso a ministrar, ficarem apenas circunscritos ao ECDES (ANGOLA, 2018). Trabalhos (NÓVOA, 2017; FERNANDES et al., 2019) demonstram que a formação e o desenvolvimento acadêmico e profissional do docente devem anteceder o início da sua carreira, ainda enquanto aluno, tomando contacto com os primeiros exemplos de desempenho docente; posteriormente, na entrada na carreira, pressupõe-se 
DOMINGOS, R. A. F., MENDES, M. da C. B. R., OLIVEIRA, D. DA S., COSTA, N. M. V. N. Qualificação acadêmica e profissional dos docentes de cursos de direito em Angola: uma análise com base nos planos de desenvolvimento institucionais

a valorização da profissão e a formação inicial, implicando uma formação profissional específica para o exercício da docência, não descurando a competência pedagógica.

Com base no enquadramento teórico deste estudo, verifica-se que a formação do docente é relevante no desenvolvimento da profissionalização. No entanto, a profissionalização transcende a iniciativa do professor, pois tem de ser criada, da parte dos gestores das IES, um ambiente adequado para o desenvolvimento e aperfeiçoamento contínuo do pessoal docente, reforçam a ideia de que as competências e habilidades adquiridas ao longo do processo formativo devem ser tidas em conta para o alinhamento do perfil de formação à área de conhecimento da disciplina a ministrar (NÓVOA, 2017).

Os principais resultados da dimensão “Ensino” são sintetizados na Tabela 7.

Tabela 7. Resultados da dimensão “Ensino (competência pedagógica)”, por PDI de cada Universidade

\begin{tabular}{|c|c|c|c|c|c|c|}
\hline & \multirow{2}{*}{ Indicadores } & \multicolumn{5}{|c|}{ Escala } \\
\hline & & $\mathrm{U} 1$ & $\mathrm{U} 2$ & U3 & $\mathrm{U} 4$ & U5 \\
\hline i & $\begin{array}{l}\text {...referência à adequação do perfil docente } \\
\text { à Unidade Curricular/UC que ministra }\end{array}$ & 2 & 2 & 2 & 2 & 2 \\
\hline ii & $\begin{array}{l}\text {...promoção de formação complementar } \\
\text { destinada aos docentes }\end{array}$ & 4 & 4 & 3 & 4 & 3 \\
\hline iii & $\begin{array}{l}\text {...exigidos requisitos mínimos ao } \\
\text { profissional para a UC a ministrar }\end{array}$ & SIM & NÃO & NÃO & NÃO & NÃO \\
\hline iv & ...é exigida agregação pedagógica & SIM & SIM & SIM & SIM & SIM \\
\hline $\mathrm{v}$ & $\begin{array}{l}\text {...existência de incentivos que estimulam a } \\
\text { participação dos docentes em atividades } \\
\text { acadêmicas da instituição }\end{array}$ & SIM & SIM & SIM & NÃO & SIM \\
\hline $\mathrm{vi}$ & $\begin{array}{l}\text {...existência de incentivos à produção de } \\
\text { materiais pedagógicos }\end{array}$ & NÃO & SIM & SIM & SIM & SIM \\
\hline
\end{tabular}

Fonte: Elaborado pelos autores (2020).

A presença do indicador (i) é pouco relevante (nível 2) nos PDI analisados. 0 indicador (ii) está presente de forma diferenciada, variando entre os níveis 3 (U3 e U5) e 4 (U1, U2 e U4), o que à partida alinha-se ao sugerido na literatura. Ao indicador (iii) é o indicador em que se regista, no conjunto dos cinco PDI, resultados mais baixos, não estando presente (NÃO) em nenhum PDI, à exceção do da U1 (SIM). No sentido oposto, 
DOMINGOS, R. A. F., MENDES, M. da C. B. R., OLIVEIRA, D. DA S., COSTA, N. M. V. N. Qualificação acadêmica e profissional dos docentes de cursos de direito em Angola: uma análise com base nos planos de desenvolvimento institucionais

verifica-se que o indicador (iv) está presente (SIM) em todos PDI. De forma também positiva, nos últimos dois indicadores, (v) e (vi), regista-se a representatividade significativa (SIM) na generalidade das Instituições, com exceção da U4 (NÃO) face à participação em atividades acadêmicas, e da U1 (NÃO) no indicador da produção de materiais pedagógicos.

Excertos: "Implementação do sistema de incentivos à requalificação; implantação de licença de estudo" (U1, p. 89); "Capacitar os docentes e pessoal em agregação pedagógica" (U4, p. 42); "Existência de projetos de agregação pedagógica" (U3, p. 28); "Promover a edição e publicação de trabalhos científicos; Editar e produzir material gráfico e bibliográfico" (U5, p. 6).

De modo geral, no que se refere aos indicadores (i) e (iii), verifica-se uma ausência explícita dos mesmos nos PDI. A este propósito, Pereira e Leite (2020) concluíram, no estudo realizado sobre o processo de Bolonha, na sua relação com a agenda da qualidade, que apesar da maioria dos docentes serem doutorados e mestres, o seu perfil acadêmico nem sempre é adequado às UC que lecionam. Por esta razão recomendam que as IE promovam formações complementares com vista à melhoria do desempenho dos docentes, recomendação esta presente nos PDI, nomeadamente no indicador da formação complementar destinada aos docentes da UO (níveis 3 e 4). No entanto, denota-se, pela análise efetuada e pelos excertos apresentados, a inexistência de ações concretas para a operacionalização deste indicador. Nesta perspetiva, Moreira (2020) defende a inclusão, no currículo de formação docente, de espaços para avaliação das escolhas sobre o que e como ensinar, familiarizando os futuros docentes com os conteúdos curriculares facilitadores do aprendizado do estudante.

Com todos PDI a evidenciarem favoravelmente (SIM) o indicador (iv) pode-se aferir que as IES atribuem relevância à formação dos docentes. Este posicionamento enquadra-se na visão da Comissão das Comunidades Europeias (2007, apud BEHRENS; JUNGES, 2018), que considera que a formação acadêmica não proporciona, por si só, os conhecimentos e as competências necessários à carreira docente, relevando a necessidade de aprendizagem contínua ao nível da formação profissional e pedagógica. Apesar das referências assinaladas quanto à formação pedagógica dos docentes e seu desenvolvimento, o que é consistente com a literatura, os resultados nesta dimensão demonstram insuficiências quanto à especificação do tipo de ações a serem desenvolvidas, em particular no que diz respeito aos docentes da Faculdade de Direito, 
DOMINGOS, R. A. F., MENDES, M. da C. B. R., OLIVEIRA, D. DA S., COSTA, N. M. V. N. Qualificação acadêmica e profissional dos docentes de cursos de direito em Angola: uma análise com base nos planos de desenvolvimento institucionais

pelo facto de os critérios de entrada na carreira docente estarem apenas circunscritos aos regulamentos normativos que indicam as condições gerais de ingresso nas diferentes categorias (FONTAINHA, 2010; PONCE, 2011).

Sobre a terceira dimensão, "Investigação", são apresentados na Tabela 8 os principais resultados.

Tabela 8. Resultados da dimensão "Investigação (competência científica)", por PDI de cada Universidade.

\begin{tabular}{|c|c|c|c|c|c|c|}
\hline \multirow{2}{*}{\multicolumn{2}{|c|}{ Indicadores }} & \multicolumn{5}{|c|}{ Escala } \\
\hline & & U1 & $\mathrm{U} 2$ & U3 & $\mathrm{U} 4$ & U5 \\
\hline $\mathrm{i}$ & $\begin{array}{l}\text {... parcerias e envolvimento de } \\
\text { docentes com Instituições e centros } \\
\text { de investigação. }\end{array}$ & 3 & 4 & 3 & 4 & 3 \\
\hline ii & $\begin{array}{l}\text {... enquadramento dos docentes em } \\
\text { programas de pesquisa }\end{array}$ & 4 & 4 & 4 & 4 & 4 \\
\hline iii & $\begin{array}{l}\ldots \text { estabelecimento de diretrizes } \\
\text { concretas para o processo de pesquisa }\end{array}$ & NÃO & SIM & SIM & SIM & SIM \\
\hline iv & $\begin{array}{l}\text {... exigido um número mínimo de } \\
\text { produtos científicos }\end{array}$ & NÃO & NÃO & NÃO & NÃO & NÃO \\
\hline $\mathrm{v}$ & $\begin{array}{l}\text {...apoios financeiros para } \\
\text { disseminação do conhecimento, dos } \\
\text { resultados de projetos de investigação }\end{array}$ & NÃO & NÃO & NÃO & NÃO & NÃO \\
\hline vi & $\begin{array}{l}\text {...incentivos para pesquisas } \\
\text { complementares }\end{array}$ & SIM & SIM & NÃO & SIM & SIM \\
\hline vii & $\begin{array}{l}\text {...incentivos para desenvolvimento de } \\
\text { materiais científicos relevantes para o } \\
\text { ensino }\end{array}$ & 1 & 2 & 3 & 3 & 3 \\
\hline viii & Incentivo à produção científica & 2 & 3 & 3 & 4 & 3 \\
\hline
\end{tabular}

Fonte: Elaborado pelos autores (2020).

Relativamente aos indicadores (i) e (ii), observa-se que todos os PDI apresentam índices elevados (níveis 3 e 4 para o primeiro e 4 para o segundo). Quanto a indicador (iii) verifica-se que apenas na U1 este indicador não é referenciado (NÃO), estando presente (SIM) nos PDI das restantes instituições. No sentido oposto, os indicadores (iv) e (v) estão 
DOMINGOS, R. A. F., MENDES, M. da C. B. R., OLIVEIRA, D. DA S., COSTA, N. M. V. N. Qualificação acadêmica e profissional dos docentes de cursos de direito em Angola: uma análise com base nos planos de desenvolvimento institucionais

ausentes (NÃO) em todos os PDI analisados. Por outro lado, o indicador (vi) está apenas ausente (NÃO) num PDI (U3). No que respeita ao indicador (vii) e (viii), a presença destes indicadores é bastante diferenciada. Assim, o primeiro indicador está pouco presente na U1 (nível 1) e na U2 (nível 2), verificando-se uma relevância relativamente mais significativa (nível 3) nas restantes instituições (U3, U4 e U5); o segundo indicador está pouco evidente (nível 2) na U1, sendo que nas U2, U3 e U5 se verifica uma maior presença (nível 3), destacando-se o PDI da U4 (nível 4).

Excertos: "Estabelecer parcerias com outras Universidades e centros de investigação nacionais e estrangeiros credíveis" (U5, p. 60); "incentivar a participação de docentes e atividade em atividade de investigação científica, com implementação de apoio financeiro" (U1. p.89); "Promover a pesquisa e Inovação Tecnológica virada as necessidades das populações" (U3, p. 18).

Relativamente aos indicadores (i) e (ii), verifica-se que, de modo geral, todos os PDI atribuem valoração positiva (nível 3 e 4). Todavia, regista-se, pelos excertos, a ausência de enunciação de ações concretas, promovendo a ideia de que as IES não planeiam de forma eficiente ações e parcerias de trabalho docente, nas quais os professores se envolvam em atividades e tarefas comuns. Para Torelló (2011), é imprescindível para o docente do ES: (a) Desenvolver e avaliar projetos; (b) Desenvolver materiais científicos atuais e relevantes para o ensino; (c) Comunicar e disseminar o conhecimento através da divulgação dos resultados de projetos de pesquisa; e (d) Concorrer para a construção de estruturas de apoio à investigação científica. Nesse seguimento, para Mainardes e Tello (2016), importa que IE definia as linhas de investigação, centros de pesquisa, linhas ou grupos de pesquisa isto é, as suas bases epistemológicas e por sua vez o pesquisador alinhar-se-á a estas.

Por fim, exibe-se na Tabela 9 os resultados obtidos na última dimensão do IA utilizado, "Extensão".

Tabela 9. Resultados da dimensão "Extensão (competência em disseminar o saber acadêmico)" por PDI de cada Universidade

\begin{tabular}{lllllll}
\hline & \multirow{2}{*}{ Indicadores } & \multicolumn{5}{c}{ Escala } \\
\cline { 3 - 7 } & & $\mathrm{U} 1$ & $\mathrm{U} 2$ & $\mathrm{U} 3$ & $\mathrm{U} 4$ & $\mathrm{U} 5$ \\
\hline $\mathrm{i} \quad \begin{array}{l}\text {... promoção de atividades que envolvam } \\
\text { meio empresarial e/ou o sector público. }\end{array}$ & 3 & 3 & 3 & 2 & 3 \\
\hline
\end{tabular}


DOMINGOS, R. A. F., MENDES, M. da C. B. R., OLIVEIRA, D. DA S., COSTA, N. M. V. N. Qualificação acadêmica e profissional dos docentes de cursos de direito em Angola: uma análise com base nos planos de desenvolvimento institucionais

... promoção de atividades de extensão de

ii forma assistencial e a integração entre ensino e $\quad \begin{array}{llllll}2 & 4 & 3 & 3 & 2\end{array}$ pesquisa

... incentivos que fomentam programas e

iii projetos de extensão contribuem para $\begin{array}{lllllll}2 & 2 & 2 & 2 & 2 & 2\end{array}$

fortalecimento de políticas públicas

... programas que promovem o trabalho entre a

iv intuição e a comunidade

NÃO SIM SIM SIM SIM

... programas que promovem o estreitamento

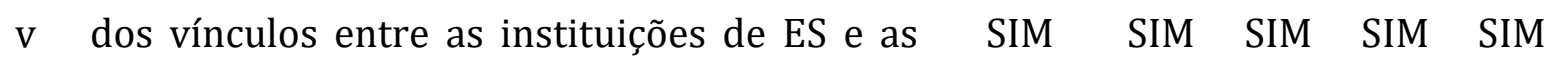
comunidades entorno da instituição

Fonte: Elaborado pelos autores (2020).

Relativamente ao indicador (i) constatou-se que o PDI da U5 é o que menos referencia (nível 2) este aspeto, apesar de os demais PDI se encontrarem num nível moderado (nível 3). Quanto ao indicador (ii), constatou-se uma presença diversificada nos PDI, com uma maior incidência no da U2 (nível 4), uma presença moderada nos da U3 e U4 (nível 3) e mais reduzida nos PDI das U1 e U5 (nível 2). É possível verificar-se que o indicador (iii) corresponde ao que obteve os resultados mais baixos em todos os PDI (nível 2). Os indicadores (iv) e (v) são os indicadores que, na globalidade, foram mais evidenciados (SIM) em todas as universidades, com exceção da U1 (NÃO) no indicador sobre os Pogramas que promovem o trabalho entre a instituição e a comunidade.

Excertos: "Resolver problemas identificados na comunidade" (U4, p. 100); "Desenvolver ações de apoio social com impacto na comunidade" (U5, p. 15); "reforçar as parcerias com instituições nacionais e internacionais, públicas e privadas para a realização de ações conjuntas no âmbito do Ensino - pesquisa e Extensão" (U2, p. 32).

Nos três primeiros indicadores denota-se incidência pouco relevante (níveis 2 e 3) na generalidade dos PDI, refletindo um posicionamento que vai em sentido oposto ao da literatura. A extensão universitária tem como objetivo básico a mobilização das IES para questões referentes à vida econômica e social, no sentido da maior aproximação da universidade com outros setores, nomeadamente com o setor empresarial (PAULA, 2013). A docência universitária exige indissociabilidade entre ensino, pesquisa e extensão, fazendo parte dessa característica integradora a produção do conhecimento, bem como a sua socialização. Para Cardoso (2016), o conhecimento científico produzido 
DOMINGOS, R. A. F., MENDES, M. da C. B. R., OLIVEIRA, D. DA S., COSTA, N. M. V. N. Qualificação acadêmica e profissional dos docentes de cursos de direito em Angola: uma análise com base nos planos de desenvolvimento institucionais

pelas IES não é para mera divulgação, mas para a melhoria das IES e das comunidades em que se inserem.

Em síntese, embora a maioria dos indicadores nas quatro dimensões (Formação, Ensino, Investigação e Extensão) se alinhem com a literatura, em particular no que se refere à QAPD assinala-se a diversidade existente entre os PDI analisados quanto à valorização de certos indicadores, e para todos eles a omissão total de ações concretas no que respeita as áreas de formação das universidades, nomeadamente em Direito. Assinala-se a preocupação e o reconhecimento da importância de se melhorar o processo de construção do PDI, para que este documento se revista de utilidade para o desenvolvimento das IES, no seu todo, mas sobretudo para a melhoria da QAPD dos docentes de cursos de Direito.

Procurando evidenciar o lugar conferido ao perfil docente no PDI, apresenta-se na Tabela 10 a síntese dos principais objetivos institucionais expressos nos PDI das cinco IES objeto de análise.

Tabela 10: Principais objetivos institucionais expressos no PDI

\begin{tabular}{ll}
\hline PDI & \multicolumn{1}{c}{ Principais Objetivos institucionais } \\
\hline U1 & Estar dotado de um quadro docente de reconhecida qualidade \\
& acadêmica e científica, estimular a aposta na ciência e tecnologia (U1, \\
& 2016, p. 68 e 70). \\
& Implantar mecanismos de atração e retenção do corpo docente \\
U2 & Nacional, explorar as potencialidades históricas da região (U2, 2017, \\
& p. 12). \\
& Enfatizar a ciência, investigação científica, desenvolvimento e \\
& inovação, organizar, produzir e gerir o conhecimento científico, \\
difundir e produzir uma cultura de conhecimento científico (U3, & \\
& 2010, p. 16). \\
& Desenvolver e difundir a investigação científica, promover a \\
& qualidade do ensino, valorizar o ser humano, suas iniciativas (U4, \\
& 2016, p. 28).
\end{tabular}


DOMINGOS, R. A. F., MENDES, M. da C. B. R., OLIVEIRA, D. DA S., COSTA, N. M. V. N. Qualificação acadêmica e profissional dos docentes de cursos de direito em Angola: uma análise com base nos planos de desenvolvimento institucionais

Organizar e ministrar cursos conducentes à obtenção dos graus

U5 acadêmicos, desenvolver atividades de investigação científica e tecnológica, recrutar e impulsionar a formação do corpo docente e de investigadores (U5, 2015, p. 9).

Fonte: Elaborado pelos autores (2020).

Verifica-se que são incluídos nos PDI das IES em Angola indicadores centrados no desenvolvimento profissional e na atratividade da carreira docente, tanto na dimensão "Ensino" como "Investigação". Por se tratar de um documento genérico, o perfil docente é tendencialmente indiferenciado. Assim, e como defendido por Fernandes et al. (2019), a incorporação de objetivos direcionados ao perfil docente no PDI substancia a diferenciação e a especificidade docente, enquanto pilar para a garantia da qualidade do processo de ensino e de aprendizagem.

\section{CONSIDERAÇÕES FINAIS}

As conclusões aqui sumariadas pretendem responder ao objetivo da nossa investigação: compreender como a QAPD, da área do Direito é assumida nos PDI de IES públicas Angolanas.

Da análise dos PDI assinalamos diferenças entre dimensões e indicadores nas cinco Instituições, depreendendo-se a falta de uniformidade das mesmas. Os PDI analisados focam-se em dimensões gerais caracterizadas por ações globais da universidade, sendo que, enquanto instrumento de gestão, deveriam incluir elementos estratégicos de desenvolvimento organizacional, nomeadamente a QAPD. Assim, sugere-se agregar aos PDI uma identificação institucional das UO e das respetivas ações estratégicas, em particular das FD.

A inexistência de diretrizes gerais sobre a estruturação do PDI é evidenciada na diferença expressiva da QAPD nos PDI, o que poderia ser resolvido com base nos pressupostos da convergência normativa, por via de um dispositivo normativo-legal. Reconhece-se deste modo, a necessidade de melhoria do processo de construção e da estrutura do PDI, para que este transite da lógica burocrática para uma racionalidade mais operacional no que diz respeito à QAPD nas FD. Procurando contribuir para a resolução deste problema, os autores do artigo estão a desenvolver um estudo centrado 
DOMINGOS, R. A. F., MENDES, M. da C. B. R., OLIVEIRA, D. DA S., COSTA, N. M. V. N. Qualificação acadêmica e profissional dos docentes de cursos de direito em Angola: uma análise com base nos planos de desenvolvimento institucionais

na análise de documentos das FD associados à operacionalização dos PDI, de forma a poder integrar orientações para uma melhor concretização dos mesmos.

\section{Referências}

ALARCÃO, I. Compreendendo e Construindo a Profissão de Professor - Da história da profissão professor ao histórico profissional de cada professor. Aveiro: Universidade de Aveiro, 2001.

ANGOLA. Resolução n.o 4/07, de 2 de fevereiro, Linhas Mestras para Melhoria da Gestão do subsistema do Ensino Superior. Diário da República, Luanda, I Série, No 15, 2007.

ANGOLA. Decreto 90/09, de 15 de Dezembro, Normas reguladoras do subsistema de ensino superior. Diário da República, Luanda, I Série, N.o 237, 2009.

ANGOLA. Decreto Presidencial 191/18, de 08 de Agosto, Estatuto Carreira Docente Ensino Superior. Diário da República, Luanda, I Série, N.o 118, 2018.

ANGOLA. Decreto Lei 32/20, de 12 de Agosto, Lei de Bases do Sistema de Educação. Diário da República, Luanda, I Série, N.o 123, 2020.

AUTORES. Qualificação Acadêmica e Profissional dos Docentes do Ensino Superior em Angola: Instrumento de Análise e sua Validação. Rev. Inter. Educ. Sup, v. 7, p. 1-27, 2021.

BEHRENS, M. A.; JUNGES, K. DOS S. Revista Diálogo Educacional. Revista Diálogo Educacional, v. 18, n. 56, p. 186-208, 2018.

BRASIL. Decreto n.o 5.773 de 09 de maio, Instruções para elaboração de plano de desenvolvimento institucional. Ministério da Educação, Portaria 4361/04 Diponivel em: http://portportal.mec.gov.br/seed/arquivos. Acesso em 12 de junho de 2017, 2006.

CARDOSO, M. R. O professor do ensino superior hoje: perspectivas e desafios. Cadernos da Fucamp, v. 15, n. 23, p. 87-106, 2016.

CHIPEATA, A. P. PESSOA B. 0 aprendizado da docência no ensino superior: experiências e saberes compartilhados por professores do curso de direito sobre o constituir-se professor. 2018. Dissertação (Mestrado em Educação) - Universidade Federal de Viçosa, Minas Geraisl, 2018.

DAMASCENO, Lorena Lins; FONTES, Mariana Gomes. Formação de professores para a qualidade na educação básica : contextos que conduziram à implementação do Parfor. Jornal de Políticas Educacionais, v. 13, n. 44, p. 1-20, 2019 Disponivel em: https://revistas.ufpr.br/ipe/article/view/67995. Acesso em 10 de Junho de 2020. 
DOMINGOS, R. A. F., MENDES, M. da C. B. R., OLIVEIRA, D. DA S., COSTA, N. M. V. N. Qualificação acadêmica e profissional dos docentes de cursos de direito em Angola: uma análise com base nos planos de desenvolvimento institucionais

ESQUINSANI, Rosimar; SOBRINHO, Sidinei. O desafio da função social docente diante das políticas educacionais em curso no Brasil. Jornal de Políticas Educacionais, v. 14, n. 17, 2020. Disponivel em: https://revistas.ufpr.br/jpe/article/view/70082. Acesso em 16 de Dezembro de 2020

FERNANDES, A; GARCIAS, A; RASOTO, V; CARVALHO, H; LIMA, I. Planejamento: um estudo do Plano de Desenvolvimento Institucional - PDI da Universidade Tecnológica Federal do Paraná ( UTFPR ). Rev. FAE, v. 22, n. 1, p. 115-136, 2019.

https://revistafae.fae.edu Acesso em 10 de junho de 2020

FONTAINHA, M. O ensino do direito na frança. Direito GV, v. 6, n. 1, p. 59-66, 2010.

FORMOSINHO, J.; MACHADO, J.; OLIVEIRA-FORMOSINHO, J. Formação, Desempenho e Avaliação de Professores. Lisboa: Edições Pe, 2010.

LINDOSO, Rosangela; DOS SANTOS, Ana. Política educacional e a avaliação em larga escala como elemento de regulação da educação. Jornal de Políticas Educacionais, v. 13, n. 1, p. 1-17, 2019. Dispovel em: https://revistas.ufpr.br/ipe/article/view/61241 Acesso em 12 de Agosto de 2020

MADERS, A.; DUARTE, I. 0 ensino jurídico frente à complexidade : crises e desafios. Conhecimento e Diversidade, v. 9, n. 19, p. 109-119, 2017. Disponivel em: https://revistas.unilasalle.edu.br/index.php Acesso em 10 de Maio de 2020

MAINARDES, Jefferson; TELLO, César. A Pesquisa no Campo da Política Educacional: Explorando Diferentes Níveis de Abordagem e Abstração. Arquivos Analíticos de Politicas Educacionais, v. 24, n. 75, p. 1-13, 2016. Disponivel em: https://www.redalyc.org Acesso em 05 de Abril de 2019

MILKIEWICZ, L.; PEDRO, J. M. A importância da formação pedagógica no curso de direito para exercício da docência na graduação. RJLB, v. 6, p. 1087-1114, 2020.

MOREIRA, A. F. B. Formação de professores e currículo: questões em debate. Ensaio: Avaliação e Políticas Públicas em Educação, p. 1-16, 2020. Disponivel em: https://www.scielo.br/scielo.php Acesso em Novembro de 2020

NÓVOA, A. Firmar a posição como professor, afirmar a profissão docente. Cadernos de Pesquisa, v. 47, n. 166, p. 1106-1133, 2017.

PAULA, J. A. A extensão universitária: história, conceito e propostas. Interfaces - Revista de Extensão da UFMG, v. 1, n. 1, p. 5-23, 2013.

PEREIRA, F. S.; LEITE, C. O Processo de Bolonha na sua relação com a agenda da qualidade - uma análise focada no perfil dos docentes que asseguram os cursos de educação básica. Techniques, Methodologies and Quality, p. 135-150, 2020.

PONCE, B. A docência universitária e as políticas públicas de formação : o caso dos cursos de direito no brasil. Revista Eletrônica Pesquisada, v. 3, n. 6, p. 200-219, 2011. 
DOMINGOS, R. A. F., MENDES, M. da C. B. R., OLIVEIRA, D. DA S., COSTA, N. M. V. N. Qualificação acadêmica e profissional dos docentes de cursos de direito em Angola: uma análise com base nos planos de desenvolvimento institucionais

ROLDÃO, M. DO C. Formação de professores e desenvolvimento profissional. Revista de Educação PUC-Campinas, v. 22, n. 2, p. 191-202, 2017. Disponivel em:

http://periodicos.puc-campinas.edu.br Acesso em junho de 2020

SILVA, E. A avaliação institucional no ensino superior em Angola. 0 desafio da qualidade e a gestão das IES. Forges, p. 1-12, 2016. Disponivel em: https://www.aforges.org/wpcontent Acesso em 20 de Agosto de 2018.

TORELLÓ, O. El Profesor Universitario: sus competencias y formación. Revista e Curriculum y formación del professor, v. 15, n. 3, p. 195-211, 2011.

UAN. PLANO DE DESENVOLVIMENTO INSTITUCIONAL - (PDI) - Universidade Agostinho Neto, 2016.

UAN. Revista Comemorativa do XL Aniversário-Universidade Agostinho Neto, Luanda, 2019.

UKB. PLANO DE DESENVOLVIMENTO INSTITUCIONAL - (PDI) - Universidade Katyavala Bwila, 2015.

UMN. PLANO DE DESENVOLVIMENTO INSTITUCIONAL - (PDI) - Universidade Mandume Ya Ndemufayo, 2010.

UNIKIVI. PLANO DE DESENVOLVIMENTO INSTITUCIONAL - (PDI) - Universidade Kimpa Vita, 2016.

UON. PLANO DE DESENVOLVIMENTO INSTITUCIONAL - (PDI) - Universidade 11 De Novembro - (PDI), 2017. 
DOMINGOS, R. A. F., MENDES, M. da C. B. R., OLIVEIRA, D. DA S., COSTA, N. M. V. N.

Qualificação acadêmica e profissional dos docentes de cursos de direito em Angola: uma análise com base nos planos de desenvolvimento institucionais

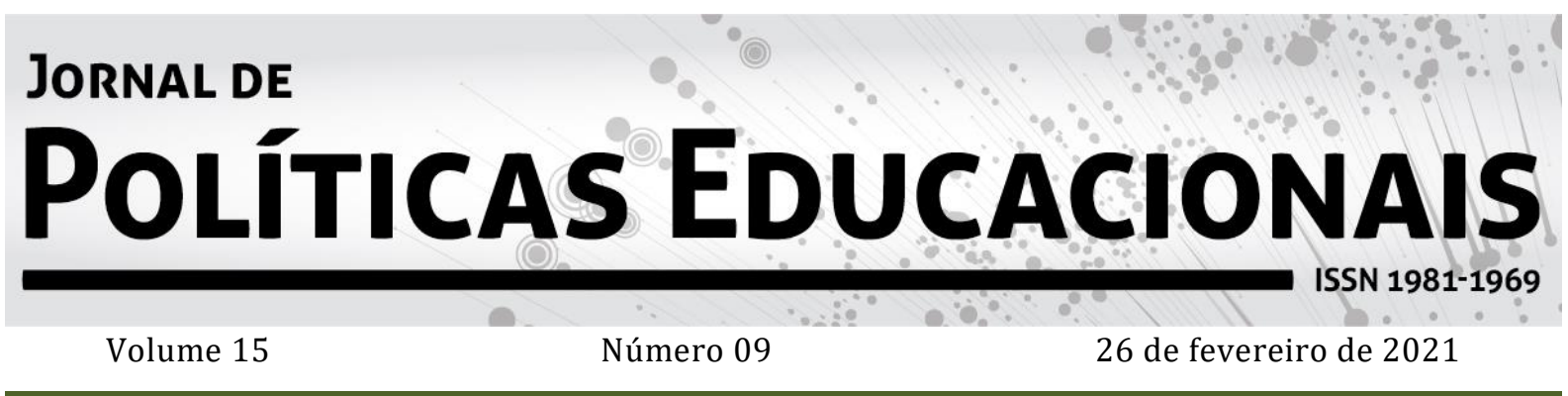

(c)

SORERIGHIS RESERNED O Copyright é retido pelo/a autor/a (ou primeiro co-autor) que outorga o direito da primeira publicação ao Jornal de Políticas Educacionais. Mais informação da licença de Creative Commons encontram-se em http://creativecommons.org/licenses/by-nc-nd/2.5. Qualquer outro uso deve ser aprovado em conjunto pelo/s autor/es e pelo periódico.

JoRnAl DE PolíticAs EdUCACIONAIS é uma publicação do Núcleo de Políticas Educacionais do Setor de Educação da Universidade Federal do Paraná - NuPE/UFPR, em consórcio com a Linha de Pesquisa em Políticas Educacionais do Programa de Pós-Graduação em Educação - PPGE/UFPR, que aceita colaboração, reservando-se o direito de publicar ou não o material espontaneamente enviado à redação. As colaborações devem ser enviadas ao NuPE/UFPR, conforme orientações contidas nas páginas do periódico na internet: http://revistas.ufpr.br/ipe.

INDEXAÇÃO:

$\begin{array}{cc}\text { BASE DE DADOS } & \text { ÍNDICES } \\ \text { Sumário.Org } & \text { Index Copernicus } \\ \text { Google Scholar } & \text { Cite Factor } \\ \text { BASE } & \\ \text { Dimensions } & \text { PORTAIS } \\ \text { Miar } & \text { LiVre } \\ & \text { Capes } \\ \text { DIRETÓRIOS } & \text { Science Open } \\ \text { Diadorim } & \text { World Wide Science } \\ \text { DOAJ } & \\ \text { Erih Plus } & \\ \text { Latindex } & \\ \text { EZB } & \\ \text { ROAD } & \\ \text { Journal 4-free } & \end{array}$

(Periódico integralmente disponível apenas em via eletrônica)

Jornal de Políticas Educacionais / Núcleo de Políticas Educacionais da Universidade Federal do Paraná NuPE/UFPR - v.1, n. 1 (1ํㅗㅇㅛ semestre de 2007) - Curitiba: NuPE/UFPR.

Volume 15, número 09 - Fevereiro de 2021

ISSN 1981-1969

1. Educação - Periódicos. 2. Política Educacional - Periódicos. I. NuPE/UFPR 
DOMINGOS, R. A. F., MENDES, M. da C. B. R., OLIVEIRA, D. DA S., COSTA, N. M. V. N.

Qualificação acadêmica e profissional dos docentes de cursos de direito em Angola: uma análise com base nos planos de desenvolvimento institucionais

Comitê Editorial:

Elisângela Scaff (UFPR)

Daniela de Oliveira Pires (UFPR)

Conselho Editorial:

Andréa Barbosa Gouveia (UFPR - Brasil), Angela Maria Martins (FCC, Brasil), Antonia Almeida Silva (UEFS, Brasil), Cesar Tello (Universidad Nacional Tres Febrero, Argentina), Cristiane Machado (Unicamp- Brasil), Elton Luiz Nardi (UNOESC, Brasil), Fernanda Saforcada (Universidad de Buenos Aires - UBA - Argentina), Gladys Beatriz Barreyro (USP - Brasil), Gilda Cardoso Araújo (UFES - Brasil), Gustavo Enrique Fischman (Arizona State University - USA), Janete Maria Lins de Azevedo (UFPE, Brasil), Jefferson Mainardes (UEPG Brasil), João Ferreira de Oliveira (UFG - Brasil), Jorge Manuel Gorostiaga (UNSAM - Argentina), Juca Gil (UFRGS - Brasil), Luciana Rosa Marques (UFPE, Brasil), Luiz Souza Júnior (UFPB - Brasil), Marcia Aparecida Jacomini (Unifesp-Brasil), Maria Dilnéia Espíndola Fernandes (UFMS, Brasil), Ney Cristina Monteiro de Oliveira (UFPA - Brasil), Nicolás Bentancur, (Universidad de la República de Uruguay), Nora Krawczyk (Unicamp- Brasil), Pedro Flores-Crespo (UAQ, México) Rodrigo da Silva Pereira (UFBA, Brasil), Robert Verhine (UFBA - Brasil), Rosana Cruz (UFPI - Brasil), Rubens Barbosa Camargo (USP - Brasil), Sebastián Donoso Díaz (Universidad de Talca - Chile), Theresa Adrião (UNICAMP - Brasil), Vera Maria Vidal Peroni (UFRGS - Brasil).

Créditos e Agradecimentos:

Revisão de Língua Portuguesa, Abstract e Resumen: Programa de apoio às publicações científicas periódicas da UFPR

Arte e diagramação: Tiago Tavares (tiagotav@gmail.com)

Jornal de Políticas Educacionais

Universidade Federal do Paraná

Setor de Educação

Núcleo de Políticas Educacionais - NuPE/UFPR

Avenida Sete de Setembro, 2645

$2^{\circ}$ andar, Sala 213

80.230-010 - Curitiba - PR - Brasil

Tel.: 41-3535-6264

jpe@ufpr.br

http://revistas.ufpr.br/jpe 